\title{
The Phylogeny of the Genera Chryseomonas, Flavimonas, and Pseudomonas Supports Synonymy of These Three Genera
}

\author{
YOJIRO ANZAI, ${ }^{*}$ YUKO KUDO ${ }^{2}$ AND HIROSHI OYAIZU ${ }^{2}$ \\ Nippon Roche Research Center, Kamakura, Kanagawa $247,{ }^{1}$ and Department of Applied \\ Biological Chemistry, Graduate School of Agriculture and Agricultural Life \\ Sciences, The University of Tokyo, Bunkyo-ku, Tokyo $113,{ }^{2}$ Japan
}

\begin{abstract}
The 16S rRNA sequences of Chryseomonas luteola, the type species of the genus Chryseomonas, and Flavimonas oryzihabitans, the type species of the genus Flavimonas, were determined. These sequences were compared with the sequences of 27 representative strains of the genus Pseudomonas. $C$. luteola and $\boldsymbol{F}$. oryzihabitans were located in the cluster that contains Pseudomonas aeruginosa, the type species of genus Pseudomonas Migula 1894, and the levels of 16S rRNA sequence homology between $P$. aeruginosa and the other two species were more than 93.9\%. All of the strains of the genus Pseudomonas sensu stricto whose sequences have been determined were included in the $P$. aeruginos $a$ cluster. These results suggested that Chryseomonas, Flavimonas, and Pseudomonas are synonymous, and we concluded that Chryseomonas and Flavimonas are junior subjective synonyms of Pseudomonas.
\end{abstract}

Chryseomonas polytricha was established by Holmes et al. in 1986 for members of group Ve-2 (3). However, C. polytricha appeared to be a junior subjective synonym of Pseudomonas luteola Kodama et al. 1985 (6), and in 1987 Holmes et al. established a new combination, Chryseomonas luteola, because of this synonymous taxonomic status (4). Pseudomonas oryzihabitans was established by Kodama et al. in 1985 (6). Holmes et al. proposed that $P$. oryzihabitans should be transferred to a new genus, the genus Flavimonas, in 1987 and established a new combination, Flavimonas oryzihabitans (4). Holmes et al. recognized that the genera Chryseomonas and Flavimonas are close relatives of the genus Pseudomonas. The establishment of the genera Chryseomonas and Flavimonas by Holmes et al. in 1987 was grounded on low levels of DNA-DNA homology between Chryseomonas and Flavimonas strains and Pseudomonas strains. However, DNA-DNA homology has been used to distinguish bacterial species and has never been powerful enough to reveal phylogenetic relationships. In recent years, it has been recognized that phylogenetic analysis based on $16 \mathrm{~S}$ rRNA sequences is necessary to draw boundaries between bacterial taxa.

In the present study the phylogenetic relationships among the genera Pseudomonas, Chryseomonas, and Flavimonas were revealed based on the almost complete 16S rRNA sequences of 24 selected Pseudomonas strains and the type strains of $C$. $l u$ teola (the type species of the genus Chryseomonas) and $F$. oryzihabitans (the type species of the genus Flavimonas). Based on the phylogenetic analysis, we concluded that Chryseomonas and Flavimonas are junior subjective synonyms of Pseudomonas.

\section{MATERIALS AND METHODS}

Bacterial strains and culture conditions. The bacterial strains used in this study are shown in Table 1 . For the sequencing study, these strains were cultured in nutrient broth (Difco) for 18 to $24 \mathrm{~h}$ at $30^{\circ} \mathrm{C}$.

Sequencing of 16S rRNA. Total DNA was extracted by the phenol method from cells cultured in liquid medium by using sodium dodecyl sulfate followed by RNase treatment. The 16S rRNA-encoding region of the DNA was amplified from the total DNA by using Taq DNA polymerase (Boehringer, Mannheim Germany) and two primers that attached to positions 10 to 25 (5'-TCGAATT

\footnotetext{
* Corresponding author. Mailing address: Nippon Roche Research Center, 200 Kajiwara, Kamakura, Kanagawa 247, Japan. Phone: 81467-47-6773. Fax: 81-467-46-5320. E-mail: yojiro.anzai@roche.com.
}

CGGATCCAGTTTGATCCTGGCTC-OH-3') and positions 1541 to 1525 (5'TCGAATTCGGATCCAAGGAGGTGATCCAGCC-OH-3') (Escherichia coll numbering) and had EcoRI and BamHI restriction sites in their $5^{\prime}$-terminal sequences. The $16 \mathrm{~S}$ ribosomal DNA (rDNA) sequences were determined by two methods, the cloning method and the direct sequencing method. In the cloning method, after digestion with a restriction enzyme, amplified DNA was purified by electrophoresis on $1.0 \%$ agarose gels and was isolated from the agarose gels with GELase (Epicentre Technologies Co., Madison, Wis.). Isolated rDNA was ligated into M13mp18 or mp19 DNA, and ligated plasmids were then transformed into $E$. coli JM109. Then single- or double-stranded plasmid DNAs extracted from the transformants were sequenced with a cycle sequencing system (Dye Primer cycle sequencing kit; Applied Biosystems, Inc., Foster City, Calif.) as specified by the manufacturer. Direct sequencing of amplified 16S rDNA was carried out as follows. Amplified DNA was purified by passing it twice through a MicroSpin S-400 HR column (Pharmacia LKB Biotechnology, Uppsala, Sweden) and the resulting DNA was used as a template. Sequencing gel electrophoresis was performed and nucleotide sequences were automatically obtained by using a model 373A or 310 DNA sequencer (Applied Biosystems, Inc.) and the protocol and software recommended by the manufacturer. Dye-labeled primers M13RP1 and -21M13 were purchased from Applied Biosystems, Inc., and the following dye-labeled primers, with five nucleotides $\left(5^{\prime}\right.$-CAGGA-OH-3') added to the $5^{\prime}$ ends of the oligonucleotides so that they were suitable for the autosequencer system, were obtained from Takara Shuzo Co., Kyoto, Japan: 520F (5'-CAGGAGTGCCAGCAGCCGCGG-OH-3'; same as positions 515 to 530), 520R (5'-CAGGAACCGCGGCTGCTGGC-OH-3'; complementary to positions 531 to 517 ), 800F (5'-CAGGAATTAGATACCCTGGTA-OH-3'; same as positions 787 to 802), 800R (5'-CAGGACTACCAGGGTATCTAAT OH-3'; complementary to positions 803 to 787$), 1100 \mathrm{~F}$ (5'-CAGGAGCAACG AGCGCAACCC-OH-3'; same as positions 1099 to 1114), and 1100R (5'-CAG GAAGGGTTGCGCTCGTTG-OH-3'; complementary to positions 1115 to 1100 ). The sequencing method used for each organism is indicated in Table 1.

Phylogenetic analysis. The sequences of the 16S rRNAs of $E$. coli (accession number V00348), Pseudomonas aeruginosa DSM 50071 ${ }^{\mathrm{T}}(\mathrm{T}=$ type strain) $(\mathrm{X} 06684)$ Pseudomonas flavescens NCPPB $3063^{\mathrm{T}}$ (U01916), and Pseudomonas mendocina ATCC $25411^{\mathbf{T}}$ (M59154) were obtained from the EMBL database for comparison. The genetic distances between sequences were estimated by using $K_{\text {nuc }}$ values (5). Then a phylogenetic tree was constructed by the neighbor-joining method (12), an evaluation of the tree was carried out by using the bootstrap method and the Clustal V program, and a total of 1,000 bootstrapped trees were generated $(1,2)$. Deleted and unknown positions were eliminated for the comparison of sequences. Positions (E. coli numbering) 70 to 100,181 to 219,447 to 487,1004 to 1036,1133 to 1141 , and 1446 to 1456 were eliminated from the com parison because the secondary structures of these regions differed between strains

GenBank, EMBL, and DDBJ accession numbers. The 16S rRNA gene sequences which we determined have been deposited in the DDBJ (DNA Data Base of Japan, Mishima, Japan), and these sequences are available from GenBank, EMBL, and DDBJ under the accession numbers shown in Table 1.

\section{RESULTS AND DISCUSSION}

The genus Pseudomonas Migula 1894 was described so that it included polarly flagellated strictly aerobic rods with a respi- 
TABLE 1. Bacterial strains examined and their 16S rRNA accession numbers and the sequencing methods used

\begin{tabular}{|c|c|c|c|}
\hline Species & Strain $^{a}$ & $\begin{array}{c}\text { Accession } \\
\text { no. }\end{array}$ & $\begin{array}{l}\text { Method } \\
\text { used for } \\
\text { sequencing }\end{array}$ \\
\hline Chryseomonas luteola & IAM $13000^{\mathrm{T}}$ & D84002 & Cloning \\
\hline Chryseomonas luteola & ATCC 43330 & D84003 & Direct \\
\hline Flavimonas oryzihabitans & IAM $1568^{\mathrm{T}}$ & D84004 & Cloning \\
\hline Pseudomonas agarici & ATCC $25941^{\mathrm{T}}$ & D84005 & Direct \\
\hline Pseudomonas alcaligenes & IAM $12411^{\mathrm{T}}$ & D84006 & Direct \\
\hline Pseudomonas amygdali & ATCC $33614^{\mathrm{T}}$ & D84007 & Direct \\
\hline Pseudomonas aureofaciens & IAM $12353^{\mathrm{T}}$ & D84008 & Direct \\
\hline Pseudomonas azotoformans & IAM $1603^{T}$ & D84009 & Cloning \\
\hline Pseudomonas caricapapayae & ATCC $33615^{\mathrm{T}}$ & D84010 & Direct \\
\hline Pseudomonas chlororaphis & IAM $12354^{\mathrm{T}}$ & D84011 & Direct \\
\hline Pseudomonas corrugata & ATCC $29736^{\mathrm{T}}$ & D84012 & Direct \\
\hline Pseudomonas fluorescens & IAM $12022^{\mathrm{T}}$ & D84013 & Cloning \\
\hline Pseudomonas fragi & IAM 12402 & D84014 & Cloning \\
\hline Pseudomonas fulva & IAM $1529^{\mathrm{T}}$ & D84015 & Cloning \\
\hline Pseudomonas mendocina & NCIB 10541 & D84016 & Cloning \\
\hline Pseudomonas mucidolens & IAM $12406^{\mathbf{T}}$ & D84017 & Cloning \\
\hline Pseudomonas nitroreducens & IAM $1439^{\mathrm{T}}$ & D84021 & Direct \\
\hline $\begin{array}{l}\text { Pseudomonas nitroreducens } \\
\text { subsp. thermotolerans }\end{array}$ & IAM 12401 & D84022 & Cloning \\
\hline Pseudomonas oleovorans & IAM $1508^{\mathrm{T}}$ & D84018 & Cloning \\
\hline "Pseudomonas pavonaceae" & IAM 1155 & D84019 & Cloning \\
\hline Pseudomonas putida & IAM $1236^{\mathrm{T}}$ & D84020 & Cloning \\
\hline Pseudomonas straminea & IAM $1598^{\mathrm{T}}$ & D84023 & Cloning \\
\hline Pseudomonas stutzeri & IAM $12668^{\mathrm{T}}$ & D84024 & Direct \\
\hline Pseudomonas synxantha & IAM $12356^{\mathrm{T}}$ & D84025 & Cloning \\
\hline Pseudomonas syringae & ATCC $19310^{\mathrm{T}}$ & D84026 & Direct \\
\hline Pseudomonas taetrolens & IAM $1653^{\mathrm{T}}$ & D84027 & Cloning \\
\hline Pseudomonas tolaasii & $\operatorname{ATCC} 33618^{\mathrm{T}}$ & D84028 & Direct \\
\hline
\end{tabular}

${ }^{a}$ IAM, Institute of Applied Microbiology, The University of Tokyo, Tokyo Japan; ATCC, American Type Culture Collection, Rockville, Md.; NCIB, National Collection of Industrial Bacteria, Aberdeen, United Kingdom.

ratory type of metabolism in which oxygen is used. Defined in this way, the genus was very heterogeneous, and several subgroups of species have been recognized, including five subgroups based on rRNA homology data (rRNA groups I to V) (9) and groups of species based on cellular fatty acid compositions and quinone systems (groups 1 to 9) (8). There was a good correlation between rRNA groups I to $\mathrm{V}$ and groups 1 to 5 based on cellular fatty acids and quinone systems. In the past two decades Pseudomonas species belonging to rRNA groups II to $\mathrm{V}$ or fatty acid and quinone groups 2 to 9 have been transferred to other genera $(10,13,14,16,17,19,20)$. At this time, the genus Pseudomonas is restricted to Palleroni rRNA group I, and only the group I strains belong to the genus Pseudomonas sensu stricto. Therefore, in the present study only the strains belonging to Palleroni rRNA group I were used for phylogenetic analyses.

Several subgroups could be differentiated in Palleroni rRNA group I $P$. aeruginosa and Pseudomonas fluorescens were placed in different clusters as a result of oligonucleotide cataloging of $16 \mathrm{~S}$ rRNA (18). Based on the results of rRNA-DNA hybridization, rRNA group I was divided into three groups, whose representative species were $P$. aeruginosa, $P$. fluorescens, and Pseudomonas syringae (9). In this study, the almost complete 16S rRNA sequences of 27 strains of the genus Pseudomonas were determined, and a phylogenetic analysis was carried out. A phylogenetic tree was drawn on the basis of these new sequences and four sequences obtained from the database (Fig. 1). The total number of nucleotides compared was 1,073 . This tree had two main clusters, although the bootstrap values for two branches were not high enough (66 and 67\%) to give a high level of confidence. The first cluster contained 16 strains and included $P$. aeruginosa DSM $50071^{\mathrm{T}}$. Pseudomonas alcaligenes IAM $12411^{\mathrm{T}}, P$. mendocina ATCC $25411^{\mathrm{T}}$ and NCIB 10541, Pseudomonas stutzeri IAM $12668^{\mathrm{T}}$, and Pseudomonas putida IAM $1236^{\mathbf{T}}$; all of these strains except $P$. putida IAM $1236^{\mathrm{T}}$ belonged to the $P$. aeruginosa subgroup of Palleroni rRNA group I. The second cluster contained 14 strains and included Pseudomonas agarici ATCC $25941^{\mathrm{T}}$, Pseudomonas chlororaphis IAM $12354^{\mathrm{T}}$, Pseudomonas aureofaciens IAM $12353^{\mathrm{T}}, P$. syringae ATCC $19310^{\mathrm{T}}$, and $P$. fluorescens IAM $12022^{\mathrm{T}}$, which belonged to the $P$. fluorescens or $P$. syringae subgroup of Palleroni rRNA group I. The results of this phylogenetic analysis based on 16S rRNA sequences were compared with the results obtained by oligonucleotide cataloging of 16S rRNA and the rRNA-DNA hybridization studies.

In this study we determined the $16 \mathrm{~S}$ rDNA sequence of "Pseudomonas pavonaceae" IAM 1155, and this strain was included on the branch that contained the Pseudomonas sensu stricto group. However, Van Landschoot et al. (15) reported that "P. pavonaceae" NCTC 10693 belongs on the Acinetobacter rRNA branch. The genus Acinetobacter is a genus of the family Moraxellaceae (11), and the Acinetobacter rRNA branch has been reported to be far from the $P$. fluorescens complex branch $(11,15)$. Strain IAM 1155 was received from H. Takahashi as ATU 224 (Laboratory of Fermentation and Microbiology, Faculty of Agriculture, University of Tokyo, Tokyo, Japan) in 1964. The history of the isolation of strain IAM 1155

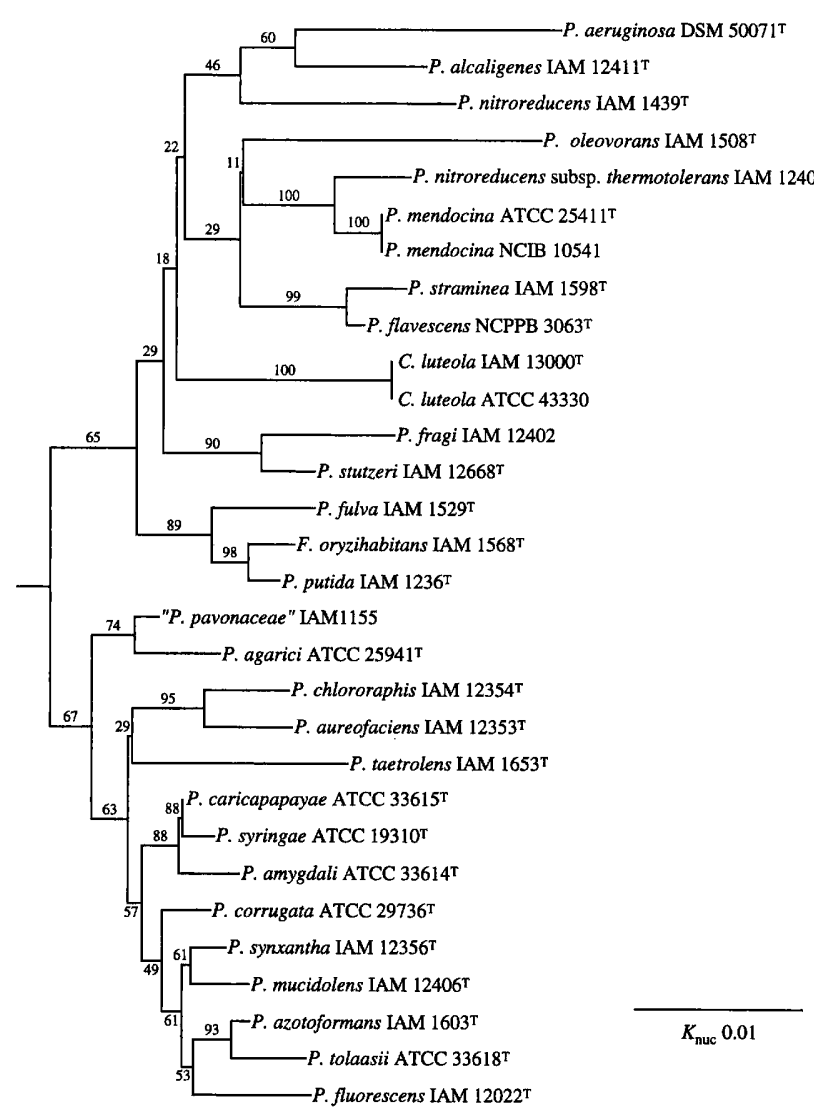

FIG. 1. Phylogenetic tree for strains of the genus Pseudomonas derived from 16S rDNA sequence similarities. The value on each branch is the estimated confidence limit (expressed as a percentage) for the position of the branch as determined by bootstrap analysis. E. coli was used as the root organism. 
was not available, but this strain was apparently isolated in the Laboratory of Fermentation and Microbiology, Faculty of Agriculture, University of Tokyo. In contrast, NCTC 10693 is the strain which was originally characterized as " $P$. pavonaceae" by Levine and Soppeland (7). Therefore, the difference between our phylogenetic analysis results and the results reported by Van Landschoot et al. (15) can be attributed to the difference in the strains used.

C. luteola (4) and F. oryzihabitans (4) were originally described as $P$. luteola and $P$. oryzihabitans, and the type strains were isolated from a human clinical specimen and a rice paddy, respectively (6). The transfers of $P$. luteola and $P$. oryzihabitans from the genus Pseudomonas were grounded on low levels of DNA-DNA hybridization (1 to 5\%) with the other Pseudomonas species (4), although the physiological and chemotaxonomic characteristics of these organisms were similar to those of the genus Pseudomonas. In our 16S rRNA sequence analysis, C. luteola IAM $13000^{\mathrm{T}}$ and ATCC 43330 and $F$. oryzihabitans IAM $1568^{\mathrm{T}}$ were found in the $P$. aeruginosa cluster (Fig. 1). The levels of homology between C. luteola IAM $13000^{\mathrm{T}}$ and $P$. aeruginosa DSM $50071^{\mathrm{T}}$ and between $F$. oryzihabitans IAM $1568^{\mathrm{T}}$ and $P$. aeruginosa DSM $50071^{\mathrm{T}}(P$. aeruginosa is type species of the genus Pseudomonas) were 94.0 and $93.9 \%$, respectively. In contrast, the levels of homology between $P$. fluorescens IAM $12022^{\mathrm{T}}$ and $P$. aeruginosa DSM $50071^{\mathrm{T}}$ and between $P$. syringae ATCC $19310^{\mathrm{T}}$ and $P$. aeruginosa DSM $50071^{\mathrm{T}}$ were 92.8 and $93.1 \%$, respectively. Thus, according to our phylogenetic analysis $C$. luteola and $F$. oryzihabitans are more closely related to $P$. aeruginosa, the type species of the genus Pseudomonas, than $P$. fluorescens and $P$. syringae are. Therefore, if $P$. fluorescens and $P$. syringae are included in the genus Pseudomonas, it is not reasonable to exclude $P$. luteola and $P$. onyzihabitans from the genus Pseudomonas. Consequently, we conclude that Chryseomonas and Flavimonas are junior subjective synonyms of Pseudomonas and that the names $P$. luteola and $P$. oryzihabitans should be used.

\section{REFERENCES}

1. Felsenstein, J. 1985. Confidence limits on phylogenies: an approach using the bootstrap. Evolution 39:783-791.

2. Higgins, D. R., A. J. Bleasby, and R. Fuchs. 1992. Clustal V: improved software for multiple sequence alignment. CABIOS 8:189-190.

3. Holmes, B., A. G. Steigerwalt, R. E. Weaver, and D. J. Brenner. 1986. Chryseomonas polytricha gen. nov., sp. nov., a Pseudomonas-like organism from human clinical specimens and formerly known as group Ve-1. Int. J. Syst. Bacteriol. 36:161-165.

4. Holmes, B., A. G. Steigerwalt, R. E. Weaver, and D. J. Brenner. 1987. Chryseomonas luteola comb. nov. and Flavimonas oryzihabitans gen. nov., comb. nov., Pseudomonas-like species from human clinical specimens and formerly known, respectively, as groups Ve-1 and Ve-2. Int. J. Syst. Bacteriol. 37:245-250.

5. Kimura, M. 1980. A simple method for estimating evolutionary rates of base substitutions through comparative studies of nucleotide sequences. J. Mol. Evol. 16:111-120.

6. Kodama, K., N. Kimura, and K. Komagata. 1985. Two new species of
Pseudomonas: $P$. oryzihabitans isolated from rice paddy and clinical specimens and $P$. luteola isolated from clinical specimens. Int. J. Syst. Bacteriol. 35:467-474.

7. Levine, M., and L. Soppeland. 1926. Bacteria in creamery wastes. Bull. Iowa State Agric. Coll. 77:1-72.

8. Oyaizu, H., and K. Komagata. 1983. Grouping of Pseudomonas species on the basis of cellular fatty acid composition and the quinone system with special reference to the existence of 3-hydroxy fatty acids. J. Gen. Appl. Microbiol. 29:17-40.

9. Palleroni, N. J. 1984. Genus I. Pseudomonas Migula 1894, p. 141-199. In N. R. Krieg and J. G. Holt (ed.), Bergey's manual of systematic bacteriology, vol. 1. The Williams \& Wilkins Co., Baltimore, Md.

10. Palleroni, N. J., and J. F. Bradbury. 1993. Stenotrophomonas, a new bacterial genus for Xanthomonas maltophilia (Hugh 1980) Swings et al. 1983. Int. J. Syst. Bacteriol. 43:606-609.

11. Rossau, R., A. Van Landschoot, M. Gillis, and J. De Ley. 1991. Taxonomy of Moraxellaceae fam. nov., a new bacterial family to accommodate the genera Moraxella, Acinetobacter, and Psychrobacter and related organisms. Int. J. Syst. Bacteriol. 41:310-319.

12. Saitou, N., and M. Nei. 1987 . The neighbor-joining method: a new method for reconstructing phylogenetic trees. Mol. Biol. Evol. 4:406-425.

13. Segers, P., M. Vancanneyt, B. Pot, U. Torck, B. Hoste, D. Dewettinck, E Felsen, K. Kersters, and P. De Vos. 1994. Classification of Pseudomonas diminuta Leifson and Hugh 1954 and Pseudomonas vesicularis Büsing, Döll, and Freytag 1953 in Brevundimonas gen. nov. as Brevundimonas diminuto comb. nov. and Brevundimonas vesicularis comb. nov., respectively. Int. J. Syst. Bacteriol. 44:499-510.

14. Tamaoka, J., D.-M. Ha, and K. Komagata. 1987. Reclassification of Pseudomonas acidovorans den Dooren de Jong 1926 and Pseudomonas testosteron Marcus and Talalay 1956 as Comamonas acidovorans comb. nov. and $\mathrm{Co}$ mamonas testosteroni comb. nov., with an emended description of the genus Comamonas. Int. J. Syst. Bacteriol. 37:52-59.

15. Van Landschoot, A., R. Rossau, and J. De Ley. 1986. Intra- and intergeneric similarities of the ribosomal ribonucleic acid cistrons of Acinetobacter. Int. J. Syst. Bacteriol. 36:150-160.

16. Willems, A., J. Busse, M. Goor, B. Pot, E. Falsen, E. Jantzen, B. Hoste, M. Gillis, K. Kersters, G. Auling, and J. De Ley. 1989. Hydrogenophaga, a new genus of hydrogen-oxidizing bacteria that includes Hydrogenophaga flava comb. nov. (formerly Pseudomonas flava), Hydrogenophaga palleroni (formerly Pseudomonas palleroni), Hydrogenophaga pseudoflava (formerly Pseudomonas pseudoflava and "Pseudomonas carboxydoflava"), and Hydrogenophaga taeniospiralis (formerly Pseudomonas taeniospiralis). Int. J. Syst. Bacteriol. 39:319-333

17. Willems, A., E. Falsen, B. Pot, E. Jantzen, B. Hoste, P. Vandamme, M. Gillis, K. Kersters, and J. De Ley. 1990. Acidovoax, a new genus for Pseudomonas facilis, Pseudomonas delafieldii E. Falsen (EF) group 13, EF group 16, and several clinical isolates, with the species Acidovorax facilis comb. nov., Acidovorax delafieldii comb. nov., and Acidovorax temperans sp. nov. Int. J. Syst. Bacteriol. 40:384-398.

18. Woese, C. R., P. Blanz, and C. M. Hahn. 1984. What isn't a pseudomonad the importance of nomenclature in bacterial classification. Syst. Appl. Microbiol. 5:179-195.

19. Yabuuchi, E., Y. Kosako, H. Oyaizu, I. Yano, H. Hotta, Y. Hashimoto, T. Ezaki, and M. Arakawa. 1992. Proposal of Burkholderia gen. nov. and transfer of seven species of the genus Pseudomonas homology group II to the new genus, with the type species Burkholderia cepacia (Palleroni and Holmes 1981) comb. nov. Microbiol. Immunol. 36:1251-1275.

20. Yabuuchi, E., I. Yano, H. Oyaizu, Y. Hashimoto, T. Ezaki, and H. Yamamoto. 1990. Proposals of Sphingomonas paucimobilis gen. nov. and comb. nov., Sphingomonas parapaucimobilis sp. nov., Sphingomonas yanoikuyae sp. nov., Sphingomonas adhaesiva sp. nov., Sphingomonas capsulata comb. nov. and two genospecies of the genus Sphingomonas. Microbiol. Immunol. 34: 99-119. 